\title{
USE OF SIMULATION IN SUPPORT OF ANALYSIS AND IMPROVEMENT OF BLOOD COLLECTION PROCESS
}

\author{
Benjamin de Mendonca \\ Andrew Phibbs \\ Joshua Vandermeer \\ Zbigniew J. Pasek \\ Industrial and Manufacturing Systems Engineering \\ University of Windsor \\ Windsor, Ontario, Canada N9B 3P4
}

\begin{abstract}
This paper deals with efforts aiming to improve processes associated with the blood specimen order and collection process in one of the Canada's largest and most diverse health care facilities. The analytical specimen testing is defined to have five sub-systems that synergize to execute the order, collection, transportation, analysis and result reporting of blood-based analytic laboratory tests. In the project current processes were defined in accordance to the standard operating procedures and other hospitals techniques and benchmarked to other known blood collection and analysis systems. The recommendations and implementation strategy to address the challenges associated with the errors and delays in the blood collection system in the emergency department at Sunnybrook were developed and prioritized using an analytical hierarchy process.
\end{abstract}

\section{INTRODUCTION}

The primary focus of every hospital is to provide care to patients. Canada has a public healthcare infrastructure wherein residents are entitled to high quality care at all healthcare facilities across each province. The goal of this structure is to provide and maintain high quality of life. The Ontario Ministry of Health and Long-Term Care is committed to providing the best care to all of those who need it.

The targets set out by the Ontario government are provincial benchmarks that each healthcare facility must achieve. An incentive plan has been put in place by the government in the form of pay-forperformance measurement. This is a source for additional funding from the government to help struggling institutions meet the challenging benchmarks that the province has set out.

Healthcare in Canada is government regulated and therefore the government oversees the performance and metrics that the individual hospitals monitor and publically report. Most healthcare organizations in the province of Ontario use the Balanced Score Card approach to monitor progress on a number of key indicators that the Ministry of Health dictates.

One such indicator that is of particular significance in the government's view of healthcare standards is the metric of patient length of stay. The principle behind this indicator has two driving components. The first component is quality of care; care should be delivered in a timely manner while maintain a high standard of patient safety in order to maintain quality. The second component to this metric is the cost implications of patient length of stay; hospital resources are expensive to maintain and operate and, as such, they should be optimized. The particular metrics that are of significant importance to this project can be viewed in Figure 1 as it relates to patient length of stay in the emergency department. 
de Mendonca, Phibbs, Vandermeer and Pasek

\begin{tabular}{|c|c|c|c|c|c|}
\hline Objective 1.2 & \multicolumn{5}{|c|}{$\begin{array}{l}\text { To improve access to our programs via the Emergency Department (ED) by } \\
\text { improving wait times in the ED }\end{array}$} \\
\hline $\begin{array}{l}\text { EXPLANATION OF } \\
\text { OBJECTIVE/INDICATORS }\end{array}$ & \multicolumn{5}{|c|}{$\begin{array}{l}\text { More timely discharge of patients from the Emergency Department (ED) } \\
\text { creates capacity in the ED. More timely transfer of emergency patients to their } \\
\text { appropriate program area beds will result in better care as well as create better } \\
\text { patient flow for the organization. } \\
\text { Sunnybrook will focus on ensuring the timely assessment of ED patients and } \\
\text { efficient and effective transfers to the proper program areas to improve } \\
\text { outcomes. }\end{array}$} \\
\hline \multicolumn{2}{|l|}{ Indicators } & Baseline & Target & $\begin{array}{c}\text { Previous Quarter } \\
\left.\text { (As at Jun } 30^{\text {th }} \quad 2009\right)\end{array}$ & $\begin{array}{c}\text { Current Cycle } \\
\text { (As at Sep } 30^{\text {th }} 2009 \text { ) }\end{array}$ \\
\hline \multicolumn{2}{|c|}{$\begin{array}{l}\text { 1. Percentage of admitted patients treated } \\
\text { within ED-LOS of } 8 \text { hours or less }\end{array}$} & $28 \%$ & $38 \%$ & $24 \%$ & $27 \%$ \\
\hline \multicolumn{2}{|c|}{$\begin{array}{l}\text { 2. Percentage of non-admitted CTAS I and II } \\
\text { patients treated within ED-LOS of } 8 \text { hours or } \\
\text { less AND non-admitted CTAS III patients } \\
\text { treated within ED-LOS of } 6 \text { hours or less }\end{array}$} & $61 \%$ & $71 \%$ & $53 \%$ & $68 \%$ \\
\hline \multicolumn{2}{|c|}{$\begin{array}{l}\text { 3. Percentage of non-admitted CTAS IV and V } \\
\text { patients treated within ED-LOS of } 4 \text { hours }\end{array}$} & $65 \%$ & $75 \%$ & $40 \%$ & $74 \%$ \\
\hline
\end{tabular}

Figure 1: Balanced Score Card Objective 1.2

Patients who visit the emergency department are given a Canadian Triage Acuity Score (CTAS) level one (1) through five (5) based on their perceived level of acuity at the point of initial triage assessment. On this scale patients' acuity refers to their health condition and how severe or life-threatening it is. Patients' with very severe presenting symptoms are considered CTAS level one (1) and patients' presenting with less severe condition are assigned a CTAS level five (5) and the other moderately severe patients are given a CTAS two (2), three (3) or four (4) based on Ministry of Health's CTAS coding formula.

Dictated by the Ontario Ministry of Health and Long-Term Care, the patient length of stay in the emergency department for CTAS 1 and 2 patients should not exceed 8 hours, for CTAS 3 patients should not exceed 6 hours, and for CTAS 4 and 5 patients should not exceed 4 hours.

Total Time Spent in the ER is the maximum amount of time 9 out of 10 patients spend in an ER receiving care, waiting for admission to a hospital bed. It begins when a patient registers until the patient is discharged or is admitted to a hospital bed. During that time, emergency room doctors and nurses may be treating a patient's condition, ordering tests and waiting for results in order to render a diagnosis and determine the best course of treatment. Sometimes treatment for a condition requires admission to a hospital bed, which may mean that the patient spends more time being cared for in the ER before a bed becomes available.

\section{PROBLEM DEFINITION}

Patient safety and emergency department length of stay are concerns of the Ministry of Health and LongTerm Care; and emergency department patient length of stay is a performance measurement monitored against government standards. Errors and delays in the blood specimen collection and analysis system directly affect the diagnostic process and in turn significantly impact the emergency department length of stay and patient safety. Studies have concluded that up to $75 \%$ of diagnostics are related to test results and up to $68 \%$ of errors in blood specimen analysis occur in the pre-analytical phase (Bonini 2002). The preanalytical phase is comprised of ordering, collecting and transporting blood specimens to the appropriate laboratories for subsequent analysis; whereas the analytical phase is the physical analysis of the specimens and the post-analytical phase is the reporting of results. In order to reduce the patient's length of stay, the timeliness of blood test results was evaluated. Errors and delays in the pre-analytic blood specimen process have been documented but feasible and effective solutions have not been realized.

This situation is of particular concern in the Sunnybrook Health Sciences' Emergency Department, where rapid feedback of laboratory results is a critical element in diagnosing patients. Errors and delays increase patients' length of stay, influence the quality of timely care provided to patients, and contributes 
to the backlog of patients in the emergency department. Duplication of work increases costs incurred by the organization and creates lack of confidence by employees in the system. This lack of confidence contributes to the systemic failures when staff creates work-around practices that fit their care provider style. In almost all cases the bottleneck processes of the patient's disposition decision, the decision to either admit or discharge, is based on diagnostic tests. These tests directly contribute to the Ministry of Health's emergency department target length of stay. In order to meet Ministry of Health stipulated performance wait times in the emergency department, these diagnostic tests need to be streamlined with the elimination of wasted time and resources.

\section{LITERATURE REVIEW}

The literature review has uncovered several research papers that are directly related to the problems in the Emergency Department at Sunnybrook Hospital. While none of these papers completely solve the issues that are the focus of this report, many of the results can be applied individually and worked into the final proposal to the Patient Safety and Quality team.

A literature review was performed with key words of patient safety, blood collection, quality improvement and errors, which returned number of papers summarized in Table 1. A common theme that was present throughout the literature was the relationship between the error rate of blood collection and when in the process the majority of these errors occurred. The specific examples in the literature referred to error rates in transfusion medicine.

Table 1: Literature Review Summary

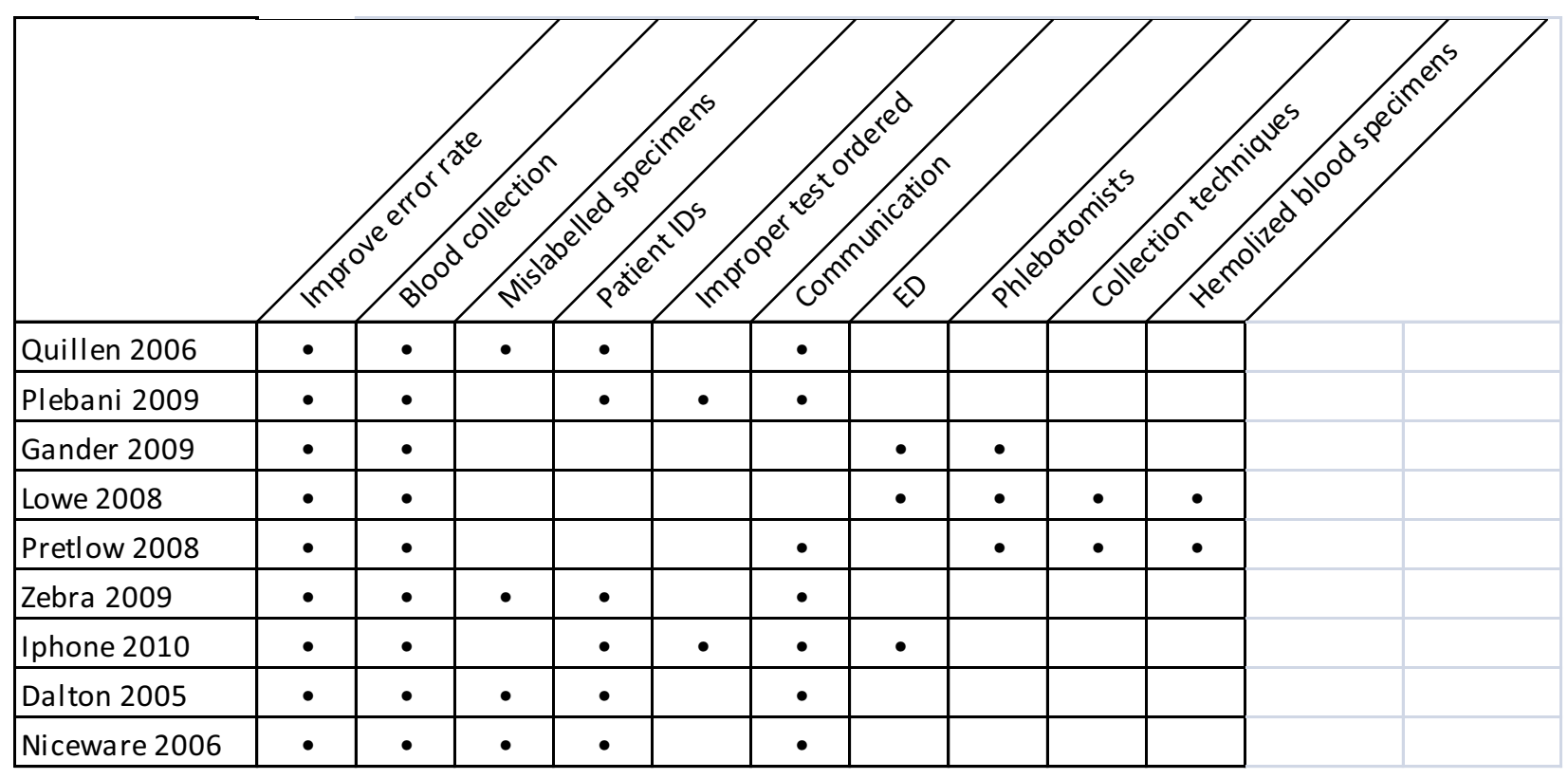

Plebani (2009) defined six domains of quality that were proposed by the US Institute of Medicine report that included: safety, effectiveness, patient-centeredness, timeliness, efficiency, and equity. Approximately two thirds of important clinical decisions about the admission and discharge of patients and the prescription of medicines are based on lab test results. Six sigma is one of the best approaches for developing quality focused goals in lab testing due to the stringent testing procedures already in place.

Another related issue (Gander 2009) is who is the most appropriate personnel to collect blood specimens. The results of the study indicated that dedicated phlebotomists decreased contaminated blood cultures from $6.5 \%$ to $3.1 \%$, which amounted to a potential savings of $\$ 4.1$ million dollars a year in this example. The recommendations of the experiment were to hire dedicated phlebotomists in the ED because 


\section{de Mendonca, Phibbs, Vandermeer and Pasek}

the estimated cost of a contaminated test is $\$ 8720$. The recommendations explained that if there were five less contaminated blood cultures a year then this would cover the yearly salary of a mid level phlebotomist $(\$ 35,650.00)$. The emergency department immediately hired a dedicated phlebotomist for all three shifts. Further, in an unrelated study the emergency department was able to reduce the rate of haemolysis in blood collection from $5.6 \%$ to $0.3 \%$ by hiring a dedicated phlebotomist to perform venipuncture collections rather than intravenous catheter.

Some other unique technologies are revolutionizing the way physicians interact with information systems. In a recent project by Apple in partnership with Mount Sinai Hospital Corporation in Toronto, Ontario has developed an application for the personal digital assistant iPhone. The VitalHub application enables physicians to remotely access secure patient records, test results, vital statistics and medical literature through a vast internal data network.

\section{UNDERSTANDING CURRENT PROCESS}

The emergency department has a new triage station where patients can be assessed and their Canadian Triage Acuity Score (CTAS) can be administered from 1 to 5. CTAS level 1 patients are the most acute patients, such as traumas, patients exhibiting stroke-like symptoms and other immediate life threatening characteristics. Whereas, a CTAS level 5 is a patient who is stable, oriented and does not exhibit any immediate life threatening symptoms, such as a sprained ankle.

The general flow of patients into the emergency department is either by the ambulatory walk-ins or by Emergency Medical Service (EMS) - the processes that are similar, but differ in priority, length and complexity. Nursing staff usually have an educated estimate at this point in time whether or not a patient will need blood collected. However, due to physician availability and decision-making power, staff members are unable to legally request a blood test without proper authorization.

Once a patient has been triaged, patients proceed to the registration phase where a patient chart, armband and other standard documentation are generated. Patients are registered based on CTAS level and then by arrival time. Upon registration, patients are then put into a queue where they wait for processing based on resource availability and their CTAS level. Once a patient has been brought into a patient assessment location the primary care nurse will perform an initial assessment and address any immediate concerns of the patient whenever possible. Physicians then assess the patient and the outcome is usually a series of action items for the nurse to execute. During this time blood tests can be ordered by the physician and processed by the nurse.

Orders consist of a written carbon copy that is to be filled out the by physician and entered into the Electronic Patient Record system (EPR-Oasis) at a computer terminal. This system interfaces with the Lab Information System (LIS) via HL7 programming language. The LIS assigns each test an accession number for processing purposes in the laboratory. Labels are generated at the nursing station for application on the blood tube at the point of care. The nurse then can proceed to the patient assessment area and collect the desired specimens, label and prepare the specimens for transportation. Specimens are transported to the core laboratory via a pneumatic tube system that is directly linked with every nursing station in the emergency department. There are four clinical areas in the emergency department called zones. Each zone has a different demographic of patients; major acute also known as green zone houses the most acute patients, minor or ambulatory care also known as purple zone houses the least acute patients. The third and fourth zones are the clinical decision unit, also known as orange zone and acute care also known as blue zone.

Once specimens are collected and transported to the lab they are then processed for analysis and a result is generated in LIS once the analysis has been completed. Turnaround times are estimated by the laboratory based on historical data and posted on the Sunnybrook intranet. LIS then interfaces with EPR via HL 7 to communicate the results for nursing staff to review. For critical results (results that are outside the normal range previously defined by clinical care providers), a phone call is made to the emergency department unit clerk (patient administrative assistant, PAA) wherein they are informed of the critical result, 


\section{de Mendonca, Phibbs, Vandermeer and Pasek}

test and the patient and are instructed to relay the information to the most responsible care provider (nurse or physician).

The Emergency Department uses Zebra printers to print bar-coded labels for automated analysis. The interface of EDIS, LIS and EPR has associated delays and limitations regarding completeness of information available on any given system. The ED also has computers on wheels which act as mobile workstations and store all blood collection materials at the patient's bedside. It is important to point out that there is no central data warehouse that tracks master data; further the systems are continually duplicating and sharing information inefficiently. In addition the aforementioned process is the ideal state of the current order, collection and transportation systems. Due to distractions, multitasking, patient acuity and the general nature and environment of an emergency department this process is not always followed. Deviations in practice lead to varied results and in some cases can lead to serious loss or injury to patients and staff.

\section{PROBLEM ANALYSIS}

The healthcare environment is unique in many ways and in order to understand the problems and effectively assess this unique environment a number of work observations were carried out to objectively overview the interworking of the emergency department. Process owners were observed and interviews were performed to obtain a baseline of general knowledge in regards to the nature of work and tasks that are routinely performed. Among these routine tasks was the collection of blood specimens for testing. Those who were interviewed noted that there were three general times when blood specimens could be collected. It was discovered that nurses collect specimens either during triage or before the patient has been brought into their assessment room; and/or after they have been brought into their assessment room but before being seen by a physician; and/or after the physician has seen and assessed the patient. This deviation in practice was due to a variety of reasons and stems from having no enforceable standard practice with respect to when in the patient's visit blood specimens are to be collected.

A secondary challenge that was noted was the impact of staff turnover and new staff understanding practice at Sunnybrook. Nurses commented on the troubling nature of not having standard training procedures or communication strategy of key core processes such as blood collection. The ever changing environment of the emergency department of a regional trauma centre was observed to have continual interruptions and distractions. Any systematic deficiencies would cause staff to create work around practices wherein they would deviate from the accepted practice to suit their specific situation.

An example of this would be the delay observed by the label printer from the time an order is entered into EPR and the time a label is generated at the nursing station. Best practice dictates that all specimens are to be labeled at the bedside but when the technologies of printing the labels delays the process, care providers perform the collection task before obtaining the labels and therefore do not label the specimens at bedside. The outcome of this deviation in practice is the creation of error potential. The process had been deviated from and in the event that either the care provider forgot, misplaced or obtained the incorrect labels for that patient a series of deviant outcomes would follow. The specimen might have been mislabeled or may not meet labeling criteria for analysis in the lab. Furthermore, these deviations in practice were observed and a need for a failure modes analysis came out of this discovery in practice.

The impact on the system for delayed blood specimen analysis and results had not yet been quantified and the impacts of errors on this system were largely unknown. The investigation into the implications of the errors and delays of the blood specimen system on patient safety, patient flow and patient wait times in the emergency department was required. Discussions with the staff of the emergency department raised questions about the requirements of the laboratory; specifically, related to the requirements of blood specimens for analysis. A detailed functional requirement breakdown was conducting with the help of process owners and experts from the emergency department and the laboratory.

A blood specimen can fail at many levels; where it was noted that the leading causes of failure included: hemolysis, clotting, mislabeling, and insufficient quantity. These failures are detected by the quality assurance checks in the specimen analyzers in the laboratory. Each of these errors has significant impacts on a patient"s safety. Each of these errors results in a test having to be reordered and recollected. 
The implications of this as it pertains to patient safety are the time delays from arrival to result, ultimately delaying the patient's treatment, which in some cases can lead to patient death. These errors also have associated cost implications, relating to an increased length of stay, and the time and materials required to complete the rework.

In the process of blood collection, many delays in the process were observed. Some of the most common delays noted included the label printing machine, reworks, critical result reporting, and double handling of the specimens. These delays have serious implications, as any delay in the process increases the time the patient must wait to receive appropriate treatment. These delays also have cost factors attached to them, included those related to reworks and the patient length of stay.

\section{PROCESS MAPS}

The flow map is a useful tool when trying to visualize the interactions of tasks, processes and systems for a particular function. The flow of patients, information and work in the emergency department is a complex and dynamic operation which needed to be divided into a specific set of tasks in order to be fully understood. The flow map that was created for the purposes of understanding both patient and information flow as it relates to the blood collection system can be viewed in Figure 2.

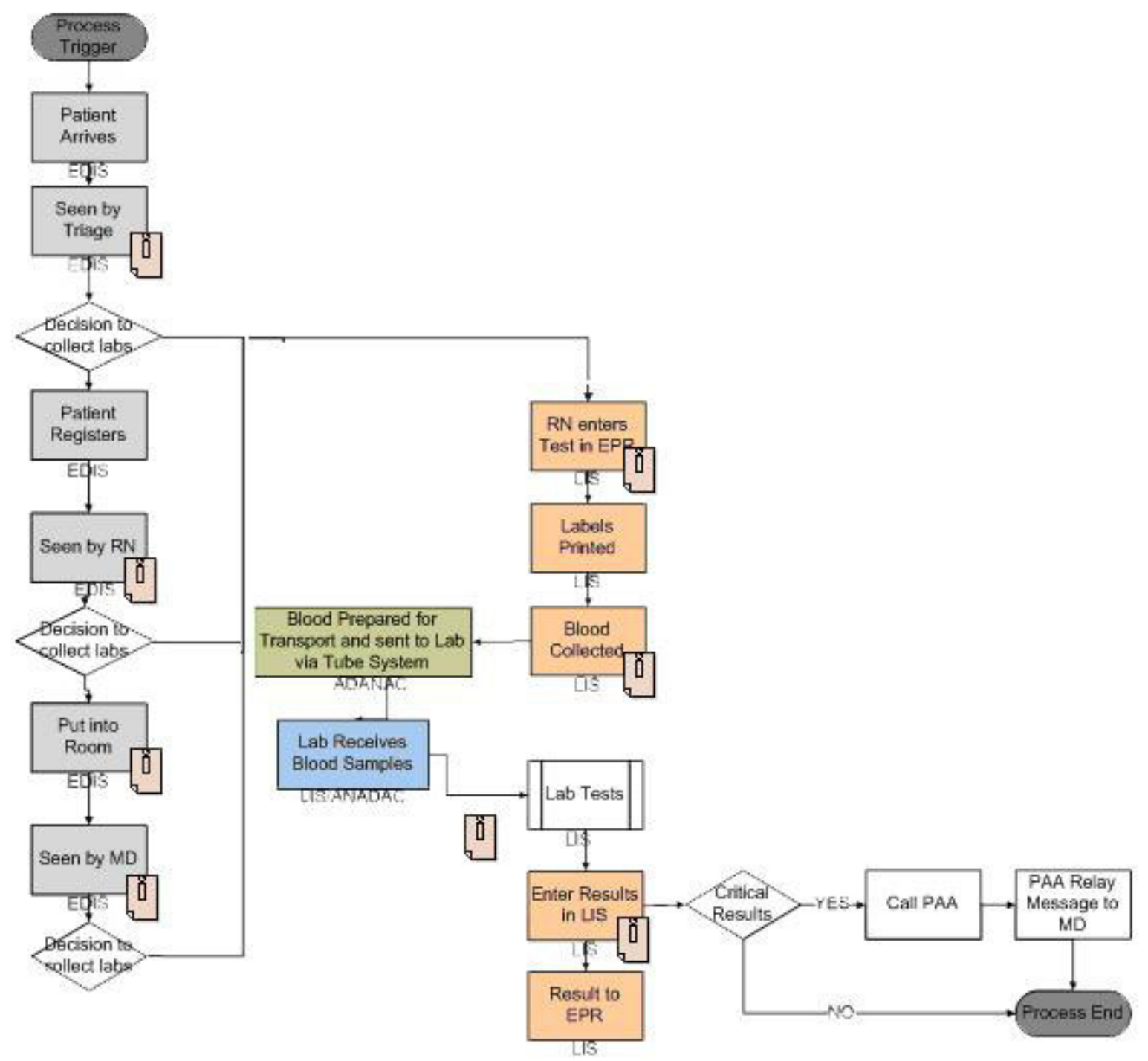

Figure 2: Process flow map 
The process flow map did not explain why errors were occurring in the system. A value stream map could have been utilized to elaborate on the deviations in process. However, it was decided that the IDEF0 Model shown in figure 3 would be a more effective tool to understand the constraints and forcing functions of the individual processes (USAF 1981).

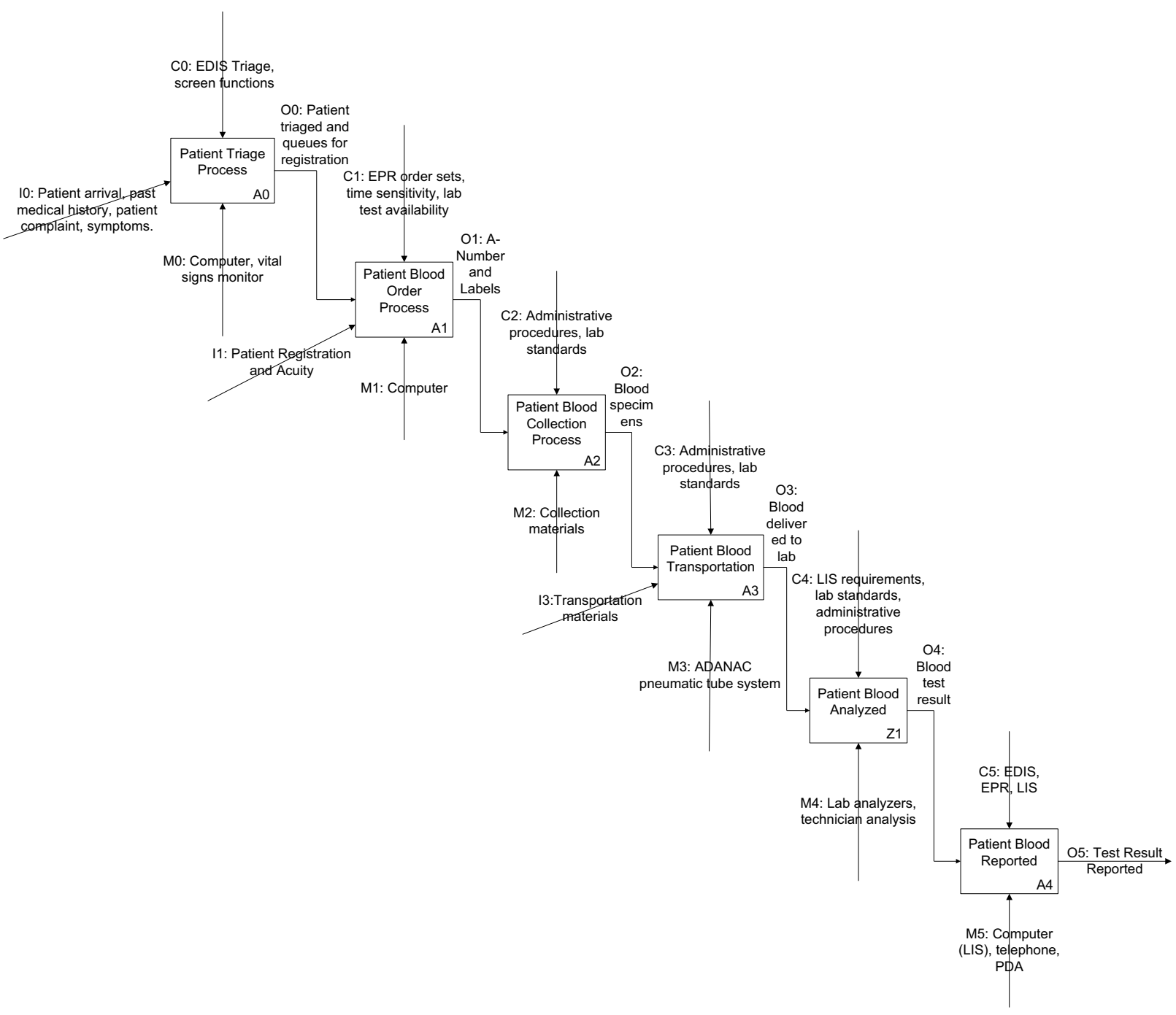

Figure 3: IDEF0 model

By understanding the flow of patients, information and how this system interacts with the overall care of a patient we can understand the need and purpose of each process in order to maximize the efficiencies of the system. Tools that can be used to illustrate and understand flow of patients and information are: flow mapping, value stream mapping and IDEF0 modeling. This is an integral step in the analysis process because it brings together all the aspects of the system and unifies them in one illustration. The box represents a specific process, much like that of a flow map. However, the arrows that feed into and flow out from the process boxes are much different. The arrow(s) on the left side of the function box are inputs to the process which are data or objects that are acted upon by the operation. The arrow(s) flowing from the right side of the box are outputs and consist of objects or data that the function has performed. Arrow(s) flowing into the top of the box are controls that are imposed on the function and are the constraints that direct the activity of the function. Controls may or may not be consumed by the function. The final 
inflow(s) from the bottom of the box are mechanisms; these are the physical aspects that make up the function and allow it to perform the tasks to reach the desired output.

The IDEF0 Model illustrated that the inefficiencies of the system were due largely in part to the lack of forcing functions and constraints on the collection and transportation processes of the system. This finding was significant in that it exposed the root cause of the errors and delays. The system design allowed variation in process, leading to its failure. By creating a standard process to be executed with constraints, mechanisms and forcing functions, the system performance and output can be made invariant.

\section{PROCESS DATA}

The distribution of patients who had blood collected at the three different decision points in the process can be viewed in Table 2. It was calculated from the actual data that the population sizes for CTAS 1 and 5 were not statistically significant. This information showed how many patients had blood collected at during the triage, after triage and after seen by a physician processes. The recommendation that followed from this observation targeted raising the percentage of CTAS 2, 3 and 4 patients who had blood collected before the patient was assessed by the physician.

Table 2: Percentages of various CTAS patients who had their blood collected

\begin{tabular}{|r|c|c|c|}
\hline & CTAS 2 & CTAS 3 & CTAS 4 \\
\hline Triage & $21.9 \%$ & $27.1 \%$ & $11.3 \%$ \\
\hline In Room & $26.0 \%$ & $29.3 \%$ & $34.0 \%$ \\
\hline After MD & $52.1 \%$ & $43.6 \%$ & $54.7 \%$ \\
\hline
\end{tabular}

\section{SIMULATIONS}

Virtual simulation was a strategy that was utilized in the formation of different recommendations and solutions to the delays in the process. Strategies can be formulated, manual processing alteration as well as technological solutions, for a streamlined process to maximize efficiencies. A simulation of blood collection was conducted to test "what-if" scenarios on the system. This defined where, when and how often this process can be executed with respect to batching, sequencing and decision-making. The first process analyzed was the ADANAC pneumatic tube transportation system, used to transfer specimen samples to and from different parts of the hospital. Using the ADANAC event log, the arrival rates of samples at each of the stations in the hospital were calculated as well as the frequencies of the various specimen delivery routes. This information was fed into MedModel to determine the efficiency of the system. MedModel is a simulation tool designed specifically for the healthcare industry (Denney 1997). MedModel is widely used in the evaluation, planning and redesign of hospitals, clinics, and other healthcare systems.

The simulation helped to identify how the tube system operated and verified that the system operates very efficiently and has minimal wait times for specimen transfer. Figure 4 shows a screenshot of various hospital locations connected to the tube system. The system was tested against various conditions and variations of processing and queuing.

A second simulation was performed to determine the effect on patient wait times of collecting blood samples from patients at triage as opposed to after being seen by the doctor. Figure 5 shows the emergency department layout and the path network for the physicians and nursing staff. Patient arrival times were obtained from EDIS and input into the MedModel software as well as the type of arrival; EMS or walk-in. The distribution of patients to each zone in the hospital; Green, Orange, Blue and Purple was also obtained from the hospital database and was modeled with the probability that patients required blood tests, the probability that a patient was admitted, and the distribution of the wait times for blood results. 
de Mendonca, Phibbs, Vandermeer and Pasek

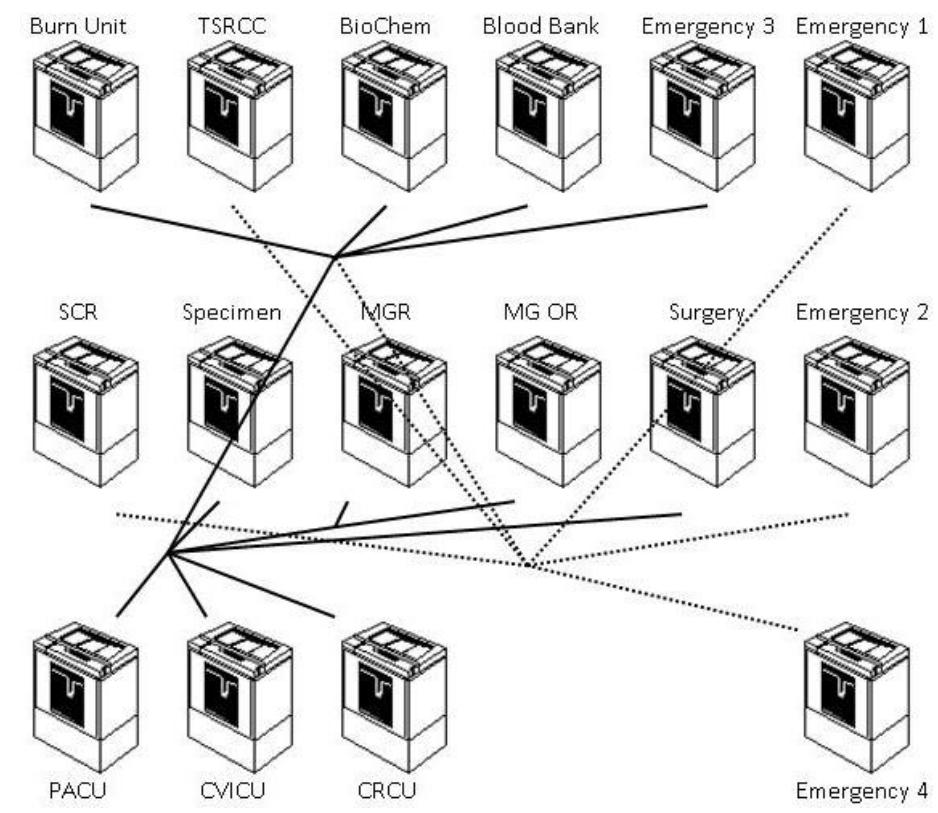

Figure 4: Topology of the ADANAC pneumatic tube system model

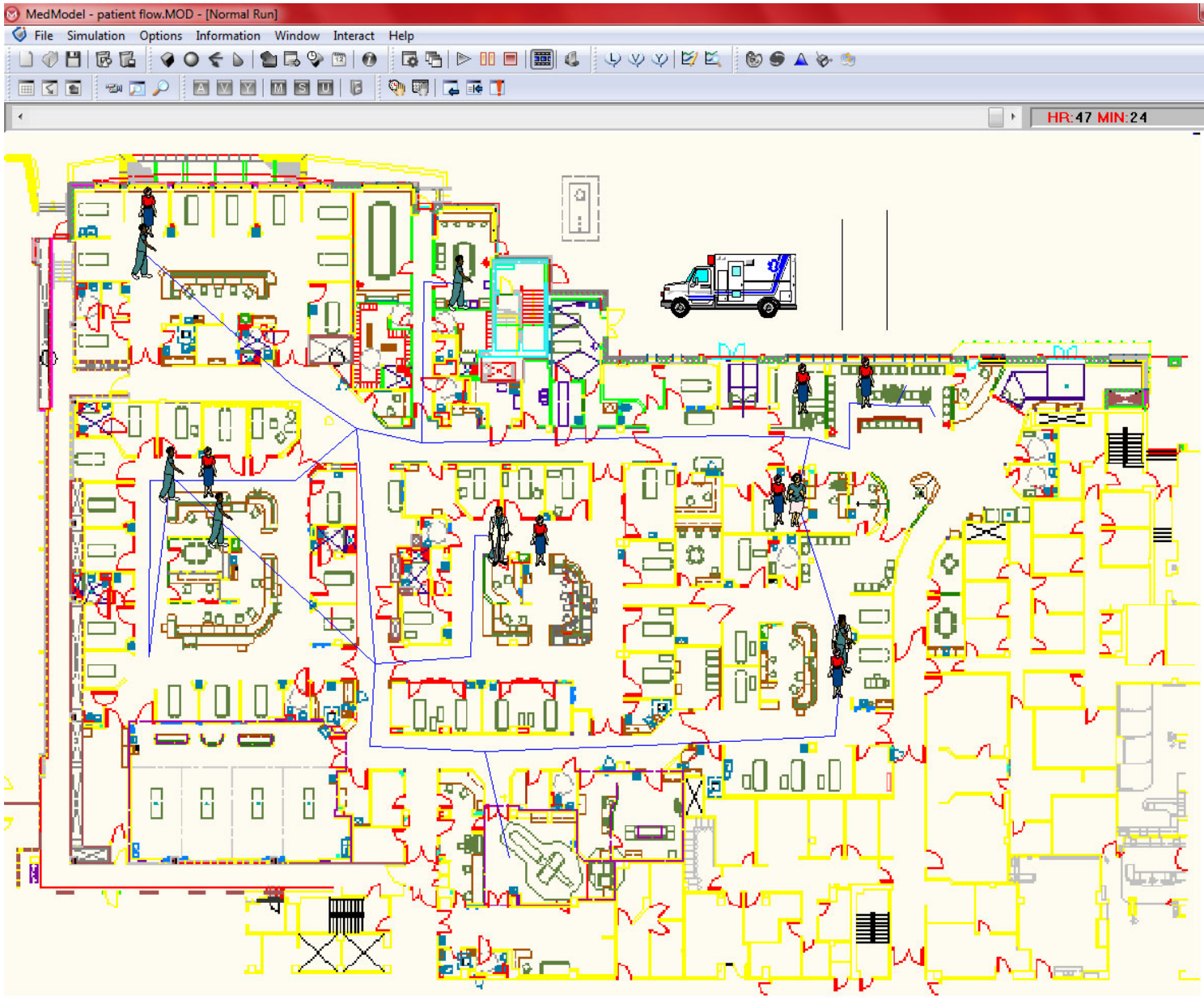

Figure 5: Patient flow simulation 


\section{SIMULATION RESULTS}

Once the process was understood on a functional level from the IDEF0 model and with respect to the processing of patients and blood specimens with regards to the Flow Map, a simulation was performed to consider various changes in process to reduce the current length of stay for patients. The ADANAC simulation yielded no significant results. This simulation tested the utilization, efficiency, and effectiveness of the system. The system utilization was observed to be $73.86 \%$ with an average wait time of 67.5 seconds and a 79 second average transit time.

The addition of a second off load station did not significantly reduce the transportation time or affect the efficiency of the system. It did however illustrate the bottleneck in the process of returning the pneumatic tubes to the units because of the priority system; this finding lead to the recommendation to obtain and install a mechanical feed for returning tubes from the main lab to the units, which would eliminate wasted time waiting for the system to clear before manually inserting another tube. This process was observed to be cumbersome for the laboratory technicians responsible for manning the station and would enable them to spend more time processing the actual specimens as opposed to feeding the tube system.

The second simulation that was performed dealt with the issue of when in the process were blood specimens collected. Table 3 shows the results of the MedModel simulation when blood is collected after consultation from the doctor. The average time in system for a patient is 593.30 minutes (9.88 hours) with 154.33 minutes (2.57 hours) being spent waiting for a doctor, nurse or a blood test and 397.33 minutes (6.62 hours) spent waiting for a room in the emergency department. Table 4 demonstrates the benefits of performing blood tests at triage to expedite the patient care process. When blood is collected at triage the average time in the system for patients is 134.86 minutes ( 2.25 hours) with 66.02 minutes ( 1.10 hours) spent waiting for a nurse, doctor or blood test to be returned and 3.95 minutes spent waiting for a room in the emergency department.

Table 3: Blood collection after MD consultation

\begin{tabular}{|l|l|l|l|l|l|l|l|}
\hline Name & Total Exits & $\begin{array}{l}\text { Current } \\
\text { qty in sys- } \\
\text { tem }\end{array}$ & $\begin{array}{l}\text { Avg. Time } \\
\text { in System }\end{array}$ & $\begin{array}{l}\text { Avg. Time } \\
\text { in Move } \\
\text { Logic }\end{array}$ & $\begin{array}{l}\text { Avg. Time } \\
\text { Waiting }\end{array}$ & $\begin{array}{l}\text { Avg. Time } \\
\text { in Opera- } \\
\text { tion }\end{array}$ & $\begin{array}{l}\text { Avg. Time } \\
\text { Blocked }\end{array}$ \\
\hline Patient & 4746 & 205 & $\begin{array}{l}593.30 \\
\text { min } \\
(9.88 \mathrm{hrs})\end{array}$ & $\begin{array}{l}2.61 \mathrm{~min} \\
(0.043 \mathrm{hrs})\end{array}$ & $\begin{array}{l}154.33 \\
\text { min } \\
(2.57 \mathrm{hrs})\end{array}$ & $\begin{array}{l}39.04 \mathrm{~min} \\
(0.65 \mathrm{hrs})\end{array}$ & $\begin{array}{l}397.33 \\
\min \\
(6.62 \mathrm{hrs})\end{array}$ \\
\hline
\end{tabular}

Table 4: Blood collection at triage

\begin{tabular}{|l|l|l|l|l|l|l|l|}
\hline Name & Total Exits & $\begin{array}{l}\text { Current } \\
\text { qty in sys- } \\
\text { tem }\end{array}$ & $\begin{array}{l}\text { Avg. Time } \\
\text { in System }\end{array}$ & $\begin{array}{l}\text { Avg. Time } \\
\text { in Move } \\
\text { Logic }\end{array}$ & $\begin{array}{l}\text { Avg. Time } \\
\text { Waiting }\end{array}$ & $\begin{array}{l}\text { Avg. Time } \\
\text { in Opera- } \\
\text { tion }\end{array}$ & $\begin{array}{l}\text { Avg. Time } \\
\text { Blocked }\end{array}$ \\
\hline Patient & 4928 & 23 & $\begin{array}{l}134.86 \\
\text { min } \\
(2.25 \mathrm{hrs})\end{array}$ & $\begin{array}{l}25.76 \mathrm{~min} \\
(0.42 \mathrm{hrs})\end{array}$ & $\begin{array}{l}66.02 \mathrm{~min} \\
(1.10 \mathrm{hrs})\end{array}$ & $\begin{array}{l}39.14 \mathrm{~min} \\
(0.65 \mathrm{hrs})\end{array}$ & $\begin{array}{l}3.95 \mathrm{~min} \\
(0.06 \mathrm{hrs})\end{array}$ \\
\hline
\end{tabular}

As illustrated in the simulation, the length of stay of patients was drastically reduced. It is important to note that this simulation software is not an optimization program and should not be considered as such. This simulation merely illustrates different scenarios imposed on the system and how it would conceptually react. 


\section{OUTCOMES}

As a result of this pilot project in the emergency department a number of recommendations were generated to reduce the blood specimen error rate and impact on the patient's length of stay. The simulation exercise was well received in illustrating the impact of standardized work. The work done with MedModel was primarily used as a tool to demonstrate potential future state performance of a standardized system that collected blood specimens at triage. The simulation was considered by Sunnybrook as a validation exercise in the recommendation to standardize practice and improve the throughput of the system by modifying current operations.

Sunnybrook Health Sciences Centre is in the process of initiating a number of projects aimed at redesigning the triage work flow and patient initial assessment, and implementing technology that would enable push alert technology to report critical results to the most appropriate physician. These new initiatives are a result of the analysis performed in this project coupled with the continual pressure from the Ministry of Health and Long Term Care to meet aggressive benchmarks in patient wait times in the Emergency Department.

\section{LIMITATIONS}

The primary limitation to this project is the lack of validation of the simulation as a true representation of the current system state. However, work on this initiative is continuing to quantify the process measures in order to validate the model. A challenge that Sunnybrook faces is the lack of congruent, rigid and reliable data in a central information system. Like any healthcare facility in the country every area of the hospital has a unique information system that is tailored to service the needs of area. These systems are not integrated or linked in any intelligent fashion and have performance measurement downfalls.

Furthermore, the system was not modeled with every limiting factor in the organization. The rate limiting factor in this simulation was assumed to be the blood collection and reporting processes; however, this is not always the case. There are other consultative services that also inhibit flow of patients through the emergency department and this simulation did not consider each specific case.

\section{ACKNOWLEDGMENTS}

The authors want to acknowledge all the assistance and support provided by the medical and administrative staff of Sunnybrook Health Science Centre, in particular Ms. Ru Taggar and Ms. Guna Budrevics.

\section{REFERENCES}

Apple. 2006. IPhone in Business - Profiles - Mount Sinai Hospital. Available via <http://www.apple.com/iphone/business/profiles/mt-sinai/> [Accessed Apr. 15, 2010].

Bonini, P, M. Plebani, F. Ceriotti, and F. Rubboli. 2002. Errors in laboratory medicine. Clinical Chemistry 48(5):691-694.

Denney, S. H. 1997. MedModel - a healthcare simulation software. In Proceedings of the 1997 Winter Simulation Conference, eds. S.G. Henderson, B. Biller, M. Hsieh, J. Shortle, J. D. Tew, R. R. Barton, 581-586. Piscataway, New Jersey: Institute of Electrical and Electronics Engineers, Inc.

Gander, R. M., L. Byrd, M. DeCrescenzo, S. Hirany, M. Bowen, and J. Baughman. 2009. Impact of blood cultures drawn by phlebotomy on contamination rates and health care costs in a hospital emergency department. Journal of Clinical Microbiology 47(4):1021-024.

Grissinger, M. 2009. Measuring up to medication safety in hospitals. P\&T - Medication Errors 34(1):1050.

Dalton, J., C. Ippolito, I. Poncet, and S. Rossini. 2005. Using RFID Technologies to Reduce Blood Transfusion Errors. White Paper by Intel Corporation, Autentica, Cisco systems and San Raffaele Hospital. 
Available via: <http://www.cisco.com/web/IT/local_offices/case_history/rfid_in_bloo d_transfusions_final.pdf>[Accessed October 3, 2010].

Kros, J. F., and R.Y. Pang. 2004. A decision support system for quantitative measurement of operational efficiency in a blood collection facility. Computer Methods and Programs in Biomedicine 74:77-89.

Lowe, G., R. Stike, M. Pollak, J. Bosley, P. O'Brien, A. Hake, G. Landis, N. Billings, P. Gordon, S. Manzella, and T. Stove. 2008. Nursing Blood Specimen Collection Techniques and Hemolysis. Journal of Emergency Nursing 34(1):26-32.

Plebani, M. 2009. Exploring the Iceberg of Errors in Laboratory Medicine. Acta Clinica Chimica 404:1623.

USAF. 1981. ICAM Architecture Part II-Volume IV - Function Modeling Manual (IDEF0). AFWAL-TR81-4023, Materials Laboratory, Air Force Wright Aeronautical Laboratories, Air Force Systems Command, Wright-Patterson Air Force Base, USA.

\section{AUTHOR BIOGRAPHIES}

BENJAMIN DE MENDONCA is a senior undergraduate student at the Department of Industrial and Manufacturing Systems Engineering at the University of Windsor. He is a member of IIE. His e-mail address is <demendeuwindsor. ca $>$.

ANDREW PHIBBS is a senior undergraduate student at the Department of Industrial and Manufacturing Systems Engineering at the University of Windsor. He is a member of IIE. His e-mail address is <phibbs@uwindsor.ca>.

JOSHUA VANDERMEER is a senior undergraduate student at the Department of Industrial and Manufacturing Systems Engineering at the University of Windsor. He is a member of IIE. His e-mail address is $<$ vandermj@uwindsor.ca>.

ZBIGNIEW J. PASEK is an Associate Professor at the Department of Industrial and Manufacturing Systems Engineering at the University of Windsor. He holds a PhD in Mechanical Engineering from the University of Michigan. His research interests include manufacturing systems automation, risk management, health care engineering and informal engineering education. He is a member of IEEE, ASME, SME, and ASEE. His e-mail address is <zjpasek@uwindsor. ca>. 